\title{
Variations in the management of pneumonia in pediatric emergency departments: compliance with the guidelines
}

\author{
Aiman Alak, HBSc; ${ }^{*}$ Jamie A. Seabrook, $\mathrm{MA}^{\dagger}{ }^{\dagger}$ Michael J. Rieder, MD, $\mathrm{PhD}^{\ddagger}$
}

\begin{abstract}
Objective: We sought to assess compliance with evidencebased guidelines for the management of pediatric pneumonia, including the variations in tests ordered and antimicrobials prescribed. Our primary hypothesis was that compliance with the treatment recommendations from the most current guidelines would be low for antimicrobial prescriptions.

Methods: We conducted a chart review at the Children's Hospital in London, Ont., to assess variation in the management of pediatric pneumonia. All patients aged 3 months to 18 years seen at the pediatric emergency department between Apr. 1, 2006, and Mar. 31, 2007, with a diagnosis of pneumonia were eligible for inclusion in the study.

Results: Compliance with management guidelines was $59.7 \%$ (95\% confidence interval $[\mathrm{Cl}] 53 \%-66 \%, n=211$ ) in children 5-18 years old and $83.0 \%(95 \% \mathrm{Cl} 80 \%-86 \%, n=605)$ in children 3 months to 5 years old. Significant variation existed in the choice of antimicrobial agent for children with pneumonia, with nonrecommended agents frequently prescribed.

Conclusion: Significant variation existed in the management of pediatric pneumonia, and adherence to guidelines was low for the group of patients aged 5-18 years. Future studies should attempt to provide guidance to distinguish between viral and bacterial etiology to allow judicious use of antimicrobials.
\end{abstract}

Keywords: pneumonia, child, pediatrics, disease management, physicians' practice patterns

\section{RÉSUMÉ}

Objectif : Nous avons cherché à évaluer la conformité aux lignes directrices fondées sur des données probantes pour la prise en charge de la pneumonie chez les enfants, y compris les variations dans les tests et les antimicrobiens prescrits. Notre hypothèse principale était que le respect des recom- mandations thérapeutiques des plus récentes lignes directrices était faible quant aux antimicrobiens prescrits.

Méthodes : Nous avons effectué un examen des dossiers à I'Hôpital pour enfants de London, en Ontario, pour évaluer la variation dans la prise en charge de la pneumonie chez les enfants. Tous les patients âgés de 3 mois à 18 ans vus au service des urgences pédiatriques entre le 1 avril 2006 et le 31 mars 2007 et ayant un diagnostic de pneumonie étaient admissibles à l'étude.

Résultats : Le respect des lignes directrices était de 59,7\% (intervalle de confiance [IC] à $95 \%$, de 53 à $66 \%, n=211$ ) chez les enfants de 5 à 18 ans et de 83,0\% (IC à $95 \%$, de 80 à $86 \%, n=605$ ) chez les enfants de 3 mois à 5 ans. Des variations significatives existaient dans le choix d'un agent antimicrobien chez les enfants atteints de pneumonie, et des agents non recommandés étaient fréquemment prescrits.

Conclusion : Des variations significatives existent dans la prise en charge de la pneumonie chez les enfants, et le respect des lignes directrices était faible pour le groupe de patients âgés de 5 à 18 ans. Les études futures devraient chercher à donner des conseils quant à la distinction entre les étiologies virales et bactériennes pour permettre une utilisation judicieuse des antimicrobiens.

\section{INTRODUCTION}

In North America, the annual incidence of pneumonia varies based on age group. For children younger than 5 years, the incidence is $30-45$ per 1000 children; for children aged 5-9 years, the incidence is 16-20 per 1000 children; for older children and adolescents, the incidence is also $16-20$ per 1000 children. ${ }^{1-4}$ Pneumonia can have devastating consequences. For example, in

From the *Department of Paediatrics, Children's Hospital, London Health Science Centre, Schulich School of Medicine \& Dentistry, University of Western Ontario, London, Ont., the †Departments of Paediatrics and Sociology, Children's Health Research Institute, University of Western Ontario, London, Ont., and the ¥Division of Emergency Medicine, Departments of Paediatrics, Medicine, Clinical Pharmacology, and Physiology and Pharmacology, Schulich School of Medicine \& Dentistry, University of Western Ontario, London, Ont.

Submitted Jun. 18, 2009; Revised Nov. 23, 2009; Accepted Dec. 14, 2009

This article has been peer reviewed.

CJEM 2010;12(6):514-9 
developing countries, sources estimate that pneumonia causes 2 million childhood deaths annually. ${ }^{5}$ The difficulty of identifying the causative agents contributes to the challenge of managing the treatment of pneumonia. Several research studies have shown that the causative agent could not be identified in approximately half of cases. ${ }^{6-20}$ As determination of etiology is difficult, empirical therapy is a common treatment course.

Canadian guidelines for the treatment of pediatric pneumonia approach the problem from an age-based, etiologic perspective (Table 1). ${ }^{21}$ The consensus group suggests therapy based on age group because of the association of age with particular causative agents. The guidelines favour antibiotics with the narrowest spectral range as well as ease of compliance. In terms of investigations, the guidelines make recommendations based on consensus and the availability of tests, because no gold standards exist for the determination of causative agents. Useful diagnostic tests include chest radiography, complete and differential blood counts, blood cultures, Gram staining and sputum culture, serologic testing for Mycoplasma pneumoniae, culture and antigen detection of viruses, a serologic test for viruses and a tuberculin skin test. Conversely, throat cultures and antigen detection of bacteria are not currently recommended. The extent to which these guidelines are followed and the outcome consequence of adherence to these guidelines for children with pneumonia is largely unknown. Kozyrskyj and coworkers $^{22}$ attempted to assess compliance with the above guidelines; however, they used an overly stringent interpretation of the guidelines.

Since the publication of these guidelines, trends that might change treatment recommendations include the use of Haemophilus influenzae type b vaccine, pneumococcal conjugate vaccine and influenza vaccine. Haemophilus influenzae type $\mathrm{b}$ vaccination was considered in the treatment guidelines and did not alter recommendations as the vaccine did not confer immunity against nontypeable Haemophilus influenzae. Influenza immunizations also have a small impact, as respiratory viruses are still found in $15 \%$ of cases. ${ }^{21}$ Further, although the introduction of pneumococcal conjugate vaccine likely decreased the frequency of pneumonia due to Streptococcus pneumonia, this organism is still an important cause of pneumonia in children..$^{23,24}$

Management of treatment using best evidence and guidelines will facilitate the delivery of high-quality health care and may be both efficient and cost-effective. Awareness of current diagnostic and management behaviour will assist in planning the modification of behaviour to produce the highest quality of care at the lowest possible cost. Judicious use of antibiotics will also reduce the prevalence of pathogens with antimicrobial resistance. ${ }^{25-27}$ In pursuit of this goal, we assessed variation in investigations, management and compliance with guidelines in the treatment of pneumonia in children admitted to the emergency department (ED) at the Children's Hospital in London, Ont. Our primary hypothesis was that compliance with treatment guidelines would be low for antimicrobial prescriptions. Our secondary hypothesis was that compliance with investigations guidelines would be high.

\section{METHODS}

Patient charts from the Children's Hospital were reviewed. The hospital is a publicly funded tertiary centre affiliated with the University of Western Ontario and uses a combination of electronic and paper-based medical records. The electronic system records tests that are ordered and the test results, and medical notes and prescription orders are stored in the paper record.

The charts of patients aged 3 months to 18 years seen at the pediatric ED between Apr. 1, 2006, and Mar. 31, 2007, with a diagnosis of pneumonia (codes 480-487, 495.9, 507 from the clinical modification of the International Classification of Disease, 9th revision [ICD-9-CM]) were considered eligible for inclusion in the study. Ethics approval was obtained from

Table 1. Summary of the Canadian guidelines for treatment of pediatric pneumonia*

\begin{tabular}{|c|c|c|c|}
\hline \multirow[b]{2}{*}{ Patient age group } & \multicolumn{3}{|c|}{ Patient setting, recommendation } \\
\hline & Outpatients & Patients in hospital & Patients in the intensive care unit \\
\hline 3 mo to $5 \mathrm{yr}$ & $\begin{array}{l}\text { Amoxicillin or erythromycin or } \\
\text { clarithromycin }\end{array}$ & Cefuroxime or ampicillin & $\begin{array}{l}\text { Cefuroxime plus (clarithromycin or } \\
\text { erythromycin) }\end{array}$ \\
\hline $5-18 \mathrm{yr}$ & Erythromycin or clarithromycin & $\begin{array}{l}\text { Erythromycin or clarithromycin (with } \\
\text { or without cefuroxime) or ampicillin }\end{array}$ & $\begin{array}{l}\text { Cefuroxime plus (clarithromycin or } \\
\text { erythromycin) }\end{array}$ \\
\hline
\end{tabular}


the institutional review board at the University of Western Ontario.

The patient's age group ( 3 mo to $5 \mathrm{yr}$ or $5-18 \mathrm{yr}$ ), investigations, antibiotic treatment and route of administration were abstracted from the chart onto a data collection sheet by a reviewer who was unaware of the study's hypothesis. Each investigation was counted once, even if a patient received the same test multiple times. Admission to hospital and recent doctor visits were also recorded. The number of patients with a positive laboratory culture test was noted.

\section{Management}

Treatment was considered compliant with management guidelines if the following criteria were met:

- outpatients 3 months to 5 years old were treated with amoxicillin, erythromycin or clarithromycin

- inpatients 3 months to 5 years old were treated with at least cefuroxime or ampicillin

- outpatients 5-18 years old were treated with erythromycin or clarithromycin

- inpatients 5-18 years old were treated with at least erythromycin, clarithromycin or ampicillin

In a subgroup analysis, antimicrobials from the same class were considered suitable substitutes. For example, azithromycin was considered equivalent to erythromycin and clarithromycin, cefprozil was considered a sufficient substitute for cefuroxime, and Clavulin was a sufficient substitute for amoxicillin.

Statistical analysis was completed using SPSS, version 15.0. Continuous variables were reported as means

Table 2. Investigations ordered in $\mathbf{8 1 6}$ children seen in the pediatric emergency department for pneumonia

\begin{tabular}{|c|c|c|}
\hline \multirow[b]{2}{*}{ Investigation } & \multicolumn{2}{|c|}{ Age group, no. (\%) } \\
\hline & $\begin{array}{c}3 \text { mo to } 5 \mathrm{yr} \\
n=605^{*}\end{array}$ & $\begin{array}{l}5-18 y r \\
n=211^{*}\end{array}$ \\
\hline Chest radiograph & 590 (97.5) & $204(96.7)$ \\
\hline $\begin{array}{l}\text { Complete and differential } \\
\text { blood countst }\end{array}$ & $105(17.4)$ & $49(23.2)$ \\
\hline Blood culturet & 84 (13.9) & $36(17.1)$ \\
\hline Viral culture† & $24 \quad(4.0)$ & $10 \quad(4.7)$ \\
\hline Throat culturet & $12 \quad(2.0)$ & 9 (4.3) \\
\hline Other†‡ & $13 \quad(2.1)$ & $4 \quad(2.0)$ \\
\hline $\begin{array}{l}\text { Positive culture in patients } \\
\text { who had cultures ordered }\end{array}$ & $15 / 124(12.1)$ & 4/55 (7.3) \\
\hline \multicolumn{3}{|c|}{$\begin{array}{l}\text { *Unless otherwise stated. } \\
+p>0.05 \text { for a difference in test use between age groups. } \\
\neq \text { Other tests include polymerase chain reaction for pertussis, fluid culture, serology } \\
\text { and fungal/yeast culture. }\end{array}$} \\
\hline
\end{tabular}

with standard deviation. Categorical variables were described as percentages with $95 \%$ confidence intervals. The $\chi^{2}$ test or Fisher exact test was used to compare proportions between groups. A 2-tailed probability of $p<0.05$ was used to establish statistical significance.

\section{RESULTS}

\section{Chart review}

A total of 816 children were seen in the pediatric ED for pneumonia between Apr. 1, 2006, and Mar. 31, 2007. Of these, 605 patients were aged 3 months to 5 years and 211 patients were aged 5-18 years. In the younger age group, 71 patients $(11.7 \%)$ were admitted to hospital, and 30 children $(14.2 \%)$ in the older age group were admitted.

\section{Investigations}

The investigations ordered are shown in Table 2. The vast majority of these tests would be considered useful by the guidelines criteria. ${ }^{21}$ Chest radiography was performed during almost all patient visits, with every 1 in 5 patients also undergoing complete and differential blood counts. The most common culture test ordered was a blood culture. Viral and throat cultures were used to a lesser extent. In the younger age group, $12.1 \%$ $(15 / 124)$ of patients who had cultures ordered yielded positive results compared with $7.3 \%$ (4/55) among patients aged $5-18$ years. Most of the positive cultures $(10 / 19)$ were for respiratory syncytial virus.

\section{Compliance with treatment recommendations}

Compliance with management guidelines was $59.7 \%$ $(126 / 211)$ in children $5-18$ years old and $83.0 \%$ $(502 / 605)$ in children 3 months to 5 years old $(p<0.001)$ (Table 3). ${ }^{21}$ Almost all outpatients received antibiotics

\begin{tabular}{|c|c|c|}
\hline \multirow[b]{2}{*}{ Age group } & \multicolumn{2}{|c|}{ No. (\%) [95\% confidence interval] } \\
\hline & Compliance & Adjusted compliance* \\
\hline $\begin{array}{l}3 \text { mo to } 5 y r, \\
n=605\end{array}$ & $502(83.0) \quad[80 \%-86 \%]$ & 599 (99.0) [98\%-99\%] \\
\hline $\begin{array}{l}5-18 \mathrm{yr} \\
n=211\end{array}$ & $126(59.7)$ [53\%-66\%] & $144(68.2)[62 \%-74 \%]$ \\
\hline
\end{tabular}


orally, and almost all patients admitted to hospital received antibiotics intravenously. If the interpretation of the guidelines was expanded to accept antimicrobials from the same drug class, the differences between age groups were even more pronounced. In this subgroup analysis, compliance with guidelines was 99.0\% (599/605) in the care of children 3 months to 5 years old, and it was $68.2 \%(144 / 211)$ in the care of children $5-18$ years old (Table 3).

Significant variation existed in the choice of antimicrobial agent for children with pneumonia (Table 4). Other than the recommended agents, children in the age group $5-18$ years also received amoxicillin $(8.5 \%$ of visits), azithromycin ( $8.5 \%$ of visits), Clavulin $(5.7 \%$ of visits), cefprozil (4.7\% of visits) and clindamycin (1.9\% of visits). Other than the recommended agents, children in the age group 3 months to 5 years also received cefprozil (6.9\% of visits), Clavulin ( $4.5 \%$ of visits), azithromycin (3.5\% of visits), cefotaxime (1.0\% of visits) and ceftriaxone (1.0\% of visits).

\section{DISCUSSION}

Despite the existence of accepted guidelines, we found considerable variation in the management of pediatric pneumonia by physicians in this Canadian pediatric ED. Although the guidelines were published in 1997, they remain the most current guidelines for the management of pediatric pneumonia. For children 5-18 years old, physician compliance with management guidelines was

Table 4. Choice of antimicrobial therapy in the treatment of pneumonia in 816 children

\begin{tabular}{|c|c|c|}
\hline \multirow[b]{2}{*}{ Antimicrobial agent or route* } & \multicolumn{2}{|c|}{ Age group, no. (\%) } \\
\hline & $\begin{array}{c}3 \mathrm{mo} \text { to } 5 \mathrm{yr} \\
n=605\end{array}$ & $\begin{array}{l}5-18 \mathrm{yr} \\
n=211\end{array}$ \\
\hline Amoxicillin & $337(55.7)$ & 18 (8.5) \\
\hline Clarithromycin & $134(22.0)$ & $126(60.0)$ \\
\hline Cefuroxime & $45 \quad(7.4)$ & $26(12.3)$ \\
\hline Cefprozil & $42 \quad(6.9)$ & 10 \\
\hline Clavulin & 27 (4.5) & $12(5.7)$ \\
\hline Azithromycin & $21 \quad(3.5)$ & 18 (8.5) \\
\hline Cefotaxime & $6 \quad(1.0)$ & $3(1.4)$ \\
\hline Ceftriaxone & $6 \quad(1.0)$ & $0 \quad(0.0)$ \\
\hline Clindamycin & $2(0.3)$ & $4 \quad(1.9)$ \\
\hline Other agents & $10(1.6)$ & $12(5.7)$ \\
\hline Oral route & $593(98.0)$ & $208(98.6)$ \\
\hline Intravenous route & 59 (9.8) & $29(13.7)$ \\
\hline $\begin{array}{l}\text { *Note that some children received ma } \\
\text { †Other agents include ceftazidime, ce } \\
\text { meropenem, tobramycin and vancom }\end{array}$ & $\begin{array}{l}\text { an } 1 \text { antimicrobial } \\
\text { xin, ciprofloxacin, }\end{array}$ & llin, erythromycin \\
\hline
\end{tabular}

$59.7 \%$, and in younger children it was $83.0 \% .{ }^{21}$ In the subgroup analysis using drug classes instead of specific agents, the compliance with guidelines was $99.0 \%$ in the younger children and $68.2 \%$ in the older group of children. Almost all outpatients received antibiotics orally, and almost all admitted patients received antibiotics intravenously. In terms of variation from guidelines, this was primarily related to the fact that a variety of nonrecommended agents were prescribed. Children in the age group 5-18 years frequently received amoxicillin, azithromycin, cefprozil, Clavulin and clindamycin. Younger children commonly received azithromycin, cefotaxime, cefprozil, ceftriaxone and Clavulin.

The significant majority of investigations ordered were consistent with guideline recommendations. ${ }^{21}$ Chest radiography was used for almost all patient visits, as radiography is the gold standard for the diagnosis of pneumonia; however, a "clinical" diagnosis (e.g., no chest radiograph) of pneumonia still occurred in this academic centre. ${ }^{28}$ Other commonly ordered tests were complete and differential blood counts and blood culture. Viral and throat cultures were used to a lesser extent. Only the use of throat cultures would be considered noncompliant with the guidelines. ${ }^{21}$ Notably, however, the extent to which these investigations changed management was limited. For example, cultures yielded positive results in $7.3 \%$ and $12.1 \%$ of patients in the older and younger age groups, respectively, mostly for viral cultures. However, this did not change the management, as $98 \%$ of all patients received antimicrobial agents. Possible explanations include the delays in obtaining viral cultures or the clinicians' suspicion of mixed bacterial and viral infections. ${ }^{14}$

Interestingly, physicians were much more compliant with the guidelines for younger compared with older patients. The reasons for this are not clear. Known barriers to implementation of guidelines include parents and physicians having issues with the efficiency of recommended therapies, fear of legal action, ${ }^{29}$ perceived lack of flexibility of guidelines and lack of agreement with the guidelines. ${ }^{30}$ Given the considerable experience with the agents recommended in young children, it is possible that the guidelines for younger children inspired more confidence than those for older children.

Our findings likely represent an overestimate of guideline adherence, as we did not consider dosing or treatment durations. In addition, the physicians involved in care were all board-certified pediatric emergency specialists at one academic centre, and, thus, adherence to guidelines might not be representative of other centres 
or other physicians. Kozyrskyj and coworkers ${ }^{22}$ also looked at evidence-based prescribing of antibiotics for children. They used a narrow definition of noncompliance (prescription of any drug other than amoxicillin or erythromycin for a child with pneumonia was considered non-evidence based), even though they were also using the same Canadian guidelines. The authors also did not make any distinction based on age groups. These points make their results difficult to interpret.

\section{Limitations}

Our study has several limitations. First, we used a retrospective chart review to assess compliance with guidelines; however, the nature of the medical record system at the Children's Hospital eliminated incomplete data. As mentioned, investigations and results were tabulated electronically, and prescription notes were photocopied. Second, we did not exclude patients with comorbidities from our study population, whereas the guidelines attempted to deal with otherwise healthy children; ${ }^{21}$ however, many children with pneumonia have comorbidities. Eliminating this subpopulation would reduce the population of patients drastically and limit generalizability. It should be noted that guidelines for children with pneumonia and other health issues do not currently exist. Third, our physician population consisted of pediatric emergency specialists at one centre, which might not be representative of the general physician population or physicians at other centres.

\section{CONCLUSION}

This study assessed the variation in management and compliance with guidelines in the treatment of pediatric pneumonia in a Canadian ED. Whereas the vast majority of investigations ordered were consistent with guidelines recommendations, we also found that significant heterogeneity existed in the types of antimicrobials prescribed for pediatric pneumonia. For antimicrobials, compliance with guidelines was much lower for patients 5-18 years old; however, the reasons for this were not clear. Further studies need to examine reasons for this discrepancy and whether adherence to guidelines actually improves clinical outcome. Our findings suggest that clinicians should be aware of the limited utility of many of the tests ordered and be more judicious in antimicrobial use. Future research could attempt to identify better methods at establishing etiology, especially distinguishing between bacterial and viral pneu- monia. This latter distinction could markedly reduce the prescription of antibiotics for pneumonia and decrease the prevalence of microbes with antibiotic resistance. Guidelines are needed for the therapy of children with pneumonia with other comorbid conditions. Finally, cost-effectiveness studies of pediatric pneumonia management are needed, particularly exploring the utility and costs of investigations.

Acknowledgment: Mr. Alak thanks the Summer Research Training Program at the Schulich School of Medicine \& Dentistry, University of Western Ontario. Dr. Rieder holds the Canadian Institutes of Health Research-GlaxoSmithKline Chair in Paediatric Clinical Pharmacology and is a Children's Health Research Institute Scientist.

Competing interests: None declared.

\section{REFERENCES}

1. Alexander ER, Foy HM, Kenny GE, et al. Pneumonia due to Mycoplasma pneumoniae. Its incidence in the membership of a co-operative medical group. N Engl 7 Med 1966;275:131-6.

2. Foy HM, Cooney MK, Maletzky AJ, et al. Incidence and etiology of pneumonia, croup, and bronchiolitis in preschool children belonging to a prepaid medical care group over a four-year period. Am J Epidemiol 1973;97:80-92.

3. Murphy TF, Henderson FW, Clyde WA Jr, et al. Pneumonia: an eleven-year study in a pediatric practice. Am 7 Epidemiol $1981 ; 113: 12-21$.

4. Wright AL, Taussig LM, Ray CG, et al. The Tucson Children's Respiratory Study: II. Lower respiratory tract illness in the first year of life. Am J Epidemiol 1989;129:1232-46.

5. Mulholland K. Childhood pneumonia mortality - a permanent global emergency. Lancet 2007;370:285-9.

6. Wang EE, Law BJ, Stephens D. Pediatric Investigators Collaborative Network on Infections in Canada (PICNIC) study of morbidity and risk factors with RSV disease. I Pediatr 1995;126:212-9.

7. Stagno S, Brasfield DM, Brown MB, et al. Infant pneumonitis associated with cytomegalovirus, chlamydia, pneumocystis, and ureaplasma: a prospective study. Pediatrics 1981;68:322-9.

8. Turner RB, Lande AF, Chase P, et al. Pneumonia in pediatric outpatients: cause and clinical manifestatations. 7 Pediatr 1987;111:194-200.

9. Claesson BA, Trollfors B, Brolin I, et al. Etiology of community-acquired pneumonia in children based on antibody responses to bacterial and viral antigens. Pediatr Infect Dis $\mathrm{J}$ 1989;8:856-62.

10. Isaacs D. Problems in determining the etiology of communityacquired childhood pneumonia. Pediatr Infect Dis 7 1989; 8:143-8. 
11. Paisley JW, Lauer BA, Mcintosh K, et al. Pathogens associated with acute lower respiratory tract infection in young children. Pediatr Infect Dis 1984;3:14-9.

12. Nohynek H, Eskola J, Laine E, et al. The causes of hospitaltreated acute lower respiratory tract infection in children. $A m$ J Dis Child 1991;145:618-22.

13. Korppi M, Heiskanen-Kosma T, Jalonen E, et al. Aetiology of community-acquired pneumonia in children treated in hospital. Eur J Pediatr 1993;152:24-30.

14. Hietala J, Uhari M, Tuokko H, et al. Mixed bacterial and viral infections are common in children. Pediatr Infect Dis 7 1989;8:683-6.

15. Ruuskanen O, Nohynek H, Ziegler T, et al. Pneumonia in childhood: etiology and response to antimicrobial therapy. Eur 7 Clin Microbiol Infect Dis 1992;11:217-23.

16. Davies HD, Matlow A, Petric M, et al. Prospective comparative study of viral, bacterial and atypical organisms identified in pneumonia in hospitalized Canadian infants. Pediatr Infect Dis J 1996;15:371-5.

17. Gendrel D, Raymond J, Moulin F, et al. Etiology and response to antibiotic therapy of community-acquired pneumonia in French children. Eur 7 Clin Microbiol Infect Dis 1997;16:388-91.

18. Heiskanen-Kosma T, Korppi M, Jokinen C, et al. Etiology of childhood pneumonia: serologic results of a prospective, population-based study. Pediatr Infect Dis J 1998;17:986-91.

19. Wubbel L, Muniz L, Ahmed A, et al. Etiology and treatment of community-acquired pneumonia in ambulatory children. Pediatr Infect Dis J 1999;18:98-104.

20. Drummond P, Clark J, Wheeler J, et al. Community acquired pneumonia: a prospective UK study. Arch Dis Child 2000;83:408-12.

21. Jadavji T, Law B, Lebel MH, et al. A practical guide for the diagnosis and treatment of pediatric pneumonia. CMAJ 1997;156:S703-11.

22. Kozyrskyj AL, Dahl ME, Chateau DG, et al. Evidence-based prescribing of antibiotics for children: role of socioeconomic status and physician characteristics. CMAJ 2004;171:139-45.

23. Albrich WC, Baughman W, Schmotzer B, et al. Changing characteristics of invasive pneumococcal disease in Metropolitan Atlanta, Georgia, after introduction of a 7-valent pneumococcal conjugate vaccine. Clin Infect Dis 2007;44:1569-76.

24. Hsu K, Pelton S, Karumuri S, et al. Population-based surveillance for childhood invasive pneumococcal disease in the era of conjugate vaccine. Pediatr Infect Dis 7 2005;24:17-23.

25. Schwartz B, Bell DM, Hughes JM. Preventing the emergency of antimicrobial resistance. JAMA 1997;278:944-5.

26. Seppala H, Klaukka T, Vuopio-Varkila J, et al. The effect of changes in consumption of macrolide antibiotics on erythromycin resistance in group A streptococci in Finland. NEngl 7 Med 1997;337:441-6.

27. Diekema DJ, Brueggemann AB, Doern GV. Antimicrobialdrug use and changes in resistance in Streptococcus pneumoniae. Emerg Infect Dis 2000;6:552-6.

28. Redd SC, Patrick E, Vreuls R, et al. Comparison of the clinical and radiographic diagnosis of paediatric pneumonia. Trans R Soc Trop Med Hyg 1994;88:307-10.

29. Bauchner H, Pelton SI, Klein JO. Parents, physicians, and antibiotic use. Pediatrics 1999;103:395-401.

30. Flores G, Lee M, Bauchner H, et al. Pediatricians' attitudes, beliefs, and practices regarding clinical practice guidelines: a national survey. Pediatrics 2000;105:496-501.

Correspondence to: Dr. Michael Rieder, Department of Paediatrics, Schulich School of Medicine, University of Western Ontario, 800 Commissioner's Rd. E, London ON N6A 4G5; mrieder@uwo.ca 